\title{
Bir El Yazma Üretim Merkezi Olarak Şiraz ve Resim Üslubunun Türkmen Dönemindeki Dönüşümü1 ${ }^{1}$
}

\author{
Derya AYDIN ${ }^{2}$
}

Atıf/C): Aydın, Derya, Bir El Yazma Üretim Merkezi Olarak Şiraz ve Resim Üslubunun Türkmen Dönemindeki Dönüşümü, Artuklu İnsan ve Toplum Bilim Dergisi 2020/5 (1), 82-89.

Öz

İran'ın Fars eyaletinde yer alan ve önemli bir kültür sanat merkezi olan Şiraz, 14. yüzyıl başlarından 16. yüzyılın ortalarına kadar bu özelliğini korumuştur. İran edebiyatına ait çeşitli eserlerin olduğu, resimli el yazmaları bu kentte, süreklilik içerisinde ve zaman zaman yerel metotlarla hazırlanmıştır. Bu metotla üretim, eserlerin sayı olarak artışına katkı sağlamıştır. El yazmaların sayı olarak arttığı zaman aralığ1 Türkmen Dönemi olarak bilinen Karakoyunlu (1351-1469) ve Akkoyunlu (13401514) beyliklerinin var olduğu zaman dilimine denk gelmiştir. Böylece yeni üretim metodu ile birlikte yeni bir dönemde Şiraz'da yerleşik olan resim üslubu yeniden yorumlanmıştır. Bu çalışmada, Şiraz kentinin önemli sanat merkezi olmasını etkileyen başlıca unsurlardan bahsedildikten sonra kentte gerçekleştirilen kitap üretimi ve mevcut üretimi şekillendiren bazı unsurlar üzerinde durulmuştur. Üretim ile birlikte Şiraz'da hazırlanan resimli kitaplarda var olan resim üslubundan bahsedilmiş ve Türkmen dönemindeki durum değerlendirilmiştir. Üslubun şekillenmesine etki eden nedenler ve konunun odaklanıldığı dönemdeki resim üslubundaki dönüşüm eldeki mevcut bilgiler ışığı altında ele alınmıştır.

Anahtar Kelimeler: Şiraz, Türkmen, El Yazma, Resim.

\section{Shiraz as a Production Centre of Manuscripts and Transformation of Illustration Style in Turcoman Era}

Citation/C): Aydın, Derya, Shiraz as a Production Centre of Manuscripts and Transformation of Illustration Style in Turcoman Era, Artuklu Human and Social Science Journal 2020/5 (1), 82-89.

\section{Abstract}

Shiraz, an important cultural and artistic centre located in Fars Province of Iran, preserved its feature from the beginning of the $14^{\text {th }}$ century to the middle of the $16^{\text {th }}$ century. Illustrated manuscripts, hosting various works of Iranian literature were prepared in continuity and from time to time by local methods in that city. Production with this method contributed to the increase in the number of works. The time interval in which manuscripts increased in numbers coincided with the era known as Turcoman Era when the Qaraqoyunlu (1351-1469) and Aqqoyunlu (1340-1514) principalities

\footnotetext{
${ }^{1}$ Bu makale, "Şiraz Nakkaşhaneleri ve Resimli SSehnameler (1470-1500)" başlığı ile Hacettepe Üniversitesi, Sosyal Bilimler Enstitüsü, Sanat Tarihi Anabilim Dalı’nda 2019 yılında tamamlanan Doktora tezinden üretilmiştir. Tez çalışmam sırasında araştırma bursu ve bilimsel destekleri ile katkı sağlayan Islamic Cultural and Relations Organization (Study Opportunity) (İslami Kültür ve İlişkiler Organizasyonu (Araştırma Firsatı)'na, Stipendienprogramm der Staatsbibliothek zu Berlin-Preußischer Kulturbesitz (Berlin-Prusya Kültür Mirası Vakfı Devlet Kütüphanesi Burs Programı)'e ve Türkiye Bilimsel ve Teknolojik Araştırma Kurumu (TÜBİTAK) yurt dışı araștırma burs programı (2017 yılı \2214-A 2 2. dönem)'na teșekkür ederim. Konu ile ilgili görseller telif hakları kapsamındadır. Bu sebeple makale içerisinde görsellere yer verilmemiştir. Okuyucular için gerekli atıflar yapılmıştır. 2 Arș. Gör. Dr., Mardin Artuklu Üniversitesi, Edebiyat Fakültesi, Sanat Tarihi Bölümü Bölümü, ayderya.85@gmail.com, ORCID: Orcid.org/0000-0002-0229-6947.
}

Geliş/Received: 13.05 .2020 , Kabul/Accepted: 27.06 .2020 


\section{Dönüşümü}

reigned. Thus, the style of painting in Shiraz was reinterpreted with the new production method within a new era. In this study, after mentioning the major factors affecting the city of Shiraz to become an important art centre, the book production in the city and some elements shaping the current production are emphasized. In addition to the production, the painting style available in the illustrated books prepared in Shiraz is also discussed and the situation in the Turcoman period is evaluated. The factors having effect on shaping the style and the transformation in the painting style in the period focussed on are dealt in our subject.

Keywords: Shiraz, Turcoman, Manuscript, Painting

\section{GíRiş}

İran'ı içerisine alan coğrafya tarih boyunca farklı siyasi hakimiyetlerin altında kalmıştır. $\mathrm{Bu}$ güçler bölgede kaldıkları süre boyunca farklı kentleri sanat üretim merkezleri haline getirmişlerdir. Özellikle İran'ın Tebriz, Herat ve Şiraz gibi şehirleri değişik dönemlerde merkez olmuş ve sanat üretiminin devam etmesine katkı sağlamıştır. Şiraz'ın bahsi geçen merkezlerinden farklı tarafı bu özelliğini uzun yıllar koruması olmuştur.

Şiraz’ın İran’ın önemli eyaletlerinden Yezd, İsfahan, Huzistan, Basra Körfezi ve Kerman yollarının kesişme noktası üzerinde olması, şehrin ele geçirilmesinde önemli bir rol oynamıştır. Bulunduğu bu nokta kenti sivil, askeri ve ticari açıdan önemli bir merkez haline getirmiştir. İlk olarak Halife Ömer zamanında (hal.634-644) Araplar tarafından ele geçirilmiştir. Şehre daha sonra gelen Büveyhioğulları'nın 10. yüzyıldaki hâkimiyetleri ve imar faaliyetleri bilinmektedir. Bundan sonra sırasıyla Şiraz’1 hakimiyetleri altına alan Salgurlu (1148-1286), İlhanlı (1256-1353), İncu (1303-1357), Muzafferi (1318-1393), Timurlu (1370-1507), Karakoyunlu (1351-1469), Akkoyunlu (1340-1514) ve Safevilerdir (1501-1736) ${ }^{3}$. Bu politik güçlerden biri olan Timurlu döneminde Şiraz ön plandadır ancak önemli siyasi ve ticari merkez olmasının yanında hiçbir zaman bir başkent olamamıştır.

Önemli bir kültür sanat merkezi olma özelliğiyle ön plana çıkan Şiraz, İran coğrafyası içerisinde yer alan diğer şehirlerden bu şekilde ayrılmıştır. Kentte el yazması üretimin başlangıcını belirlemek zor olsa da 14. yüzyıl başlarından 16. yüzyıl ortalarına kadar, önemli bir bölümünü el yazmalarının oluşturduğu eserler üretilmiştir. Bunların içerisinde İran edebiyatına ait çeşitli eserlerin çok sayıda örneği bulunur. Ayrıca, Şiraz'da üretilen kitaplarda bilenen ve uygulanan kitap üretim tekniklerinin yanı sıra yerel ve kendine has yöntemlerin de denenmesi oldukça dikkat çekicidir. Böylece özellikle 15. yüzyılın son çeyreğinde yoğun bir kitap artışı ile karışılmaktadır.

Kitap üretimindeki atış Şiraz’da Türkmen Dönemine denk gelmektir. Dönemin “Türkmen” ismi altında değerlendirilmesinde, iki önemli beylik olan Karakoyunlu ve Akkoyunlu beyliklerinin eş zamanlı varlık göstermeleri sebep olmuştur. Bu yeni dönem hem siyasi anlamda yenilikler getirmiş hem de sanat üretimini yeniden şekillenmesini sağlamıştır. Dolayısıyla bu çalışmada “ticari” üretim ile oluşan resim üslubu ve "Türkmen Dönemi” bağlamları üzerinde durulmaya çalışılmıştır.

Bu kavramlarla birlikte sanat üretiminde Şiraz kentinin etkisini de göz ardı etmemek gerekir. Kentte 14. yüzyılın başından itibaren hâkim olan farklı siyasi güçlerin, Şiraz'ın bu özelliğine destek olduğu bilinmektedir. Dolayısıyla kent uzun yıllar boyunca el yazmaları için bir üretim merkezi olma özelliğini korumuştur. Şiraz'da 14. yüzyıldan 15. yüzyılın sonuna kadar kitap üretiminde

\footnotetext{
${ }^{3}$ Şiraz'a hâkim olan politik güçler hakkında ayrıntılı bilgi bkz: Uzunçarşılı, 1969, Sümer, 1989; 2001, Özgüdenli, 2010; Limbert, 2004; Kurtuluş, 2000; Aka, 2012; Gündüz, 2008.
} 


\section{AYDIN}

izlenebilen süreklilik, belirli bir resim üslubunun oluşmasını sağlamıştır. Hazırlandıkları dönemler, hamileri veya sanatçıları farklı olsa da resim üslubunda yerleşik anlayış etkilidir. Böylece resim üslubunun Şiraz'daki şekillenişini takip edilebilmektedir. Bu durum özellikle Türkmen dönemi olarak adlandırılan Karakoyunlu ve Akkoyunlu döneminde daha belirgin hale gelmiştir. Resimli kitapların sayı olarak artışı ve bu artışla birlikte yeniden şekillenen üslubun değerlendirmesi gerekir.

\section{Şiraz Resim Üslubu ve Türkmen Dönemindeki Dönüşümü}

Şiraz, Güney İran’ın Fars eyaletinde yer alıp, Basra denizine yakın konumuyla daima önemli bir kent olma özelliğini korumuştur. Kentte hâkimiyet kuran güçlü yöneticiler ve kitap sanatıyla ilgilenen hamiler yazma eser üretimini desteklemeleriyle Şiraz önemli bir el yazma üretim merkezi olmuştur. Öte yandan, bu üretimde kentin ticari açıdan işlek bir konuma sahip olması ve sanat üretiminde tüccar sınıfının etkisi de azımsanmayacak boyutta ulaştırmıştır ${ }^{4}$. 1471 yılından itibaren İran’1 da içine alan bölgeyi ziyaret eden ve Şiraz'a da uğrayan Venedik elçisi Josefa Barbaro (Barbaro-Contarini, 1873:74) şehrin güzelliğini ve zenginliğini belirtirken burada çok sayıda insanın tüccar olduğunu belirtmiştir.

Tüccar sınıfın kentteki varlığı Şiraz'daki sanat üretimine farklı bir yön vermiştir. Talepler kentte özellikle 15. yüzyılın son çeyreğinde yeni ve sürekli bir üretim yöntemini beraberinde getirmiştir. Dolayısıyla el yazmalarında sayı olarak bir artış görülmeye başlamış ve İran edebiyatının beğenilen örneklerinden hazırlanan resimli el yazmaları hazırlanmıştır.

Şiraz'daki siyasi ortam, ticari faaliyetler ve hamilerin etkin rollerinin yanı sıra, içinde bulunulan koşulların da üretimi doğrudan etkilediği anlaşılmaktadır. Budak Kazvini’nin (1575-77) Şiraz'da üretilen kitaplar ile ilgili anlatısı, mevcut üretim için uygulanan sistemin anlaşılmasında yol göstericidir. Kazvini, Şiraz'da pek çok nestalik ustasının eserleri kopya ettiklerini ve kopyaların birinin diğerinden ayırt edilemeyeceğini belirtmiştir. Ayrıca Şiraz'daki her evde ailenin bütün fertlerinin kitap ile ilgili bir işle meşgul olduğunu, kadınların okuma yazma bilmemelerine rağmen eser kopya edebildiklerini ve böylece binlerce kitabın üretildiğini ifade etmiştir (AkimushkinIvanov, 1979: 50; Bağc1, 1993: 45).

Şiraz'daki ticari faaliyetler, kentteki sanat üretiminin canlılığına ve sürekliliğine katkı sağlamıştır. 15. yüzyılın ikinci yarısından itibaren hazırlanan kitaplar, "ticari” kavramı ile birlikte değerlendirilmiştir (Robinson, 1967: 95). Bu kavramın kullanılmasındaki ilk neden, 1440-1600 yılları arasındaki kitap üretimindeki artışın dikkat çekici bir hâl alması ve aynı yıllarda Şiraz’ın dışındaki merkezlerde üretilen kitap sayısının bir buçuk katına yükselmiş olmasıdır. Kitapların kimler tarafından yaptırıldığının bilinmemesi de bu terimin kullanılmasının diğer nedenidir (Robinson, 1967: 95; Uluç, 2006: 22). Hatta bazı araştırmacılar bu durumun 15. yüzyılın sonu ve 16. yüzyılın ilk yarısına kadar devam ettiğini söylenmiştir (Titley, 1983: 95).

Güçlü hükümdarların himayesi el yazma üretimine yön veren en önemli etkenlerden olmuştur. Nitekim siyasi güçlerin değişsen hâkimiyetleri, sanat üretimini destekleyen kişilerin de değişmesine sebep olmuştur. Bu kişilerin hamiliği, sanata desteği ve bu desteğin karşılığındaki talepleri, üretimin şekillenmesinde belirleyici ögelerden olmuştur.

15. yüzyılda Şiraz’ın resimli el yazma üretiminin merkezi konumuna gelmesi, Timurlular döneminde olmuştur. Timurlu mirzası ve Fars bölgesi valisi İskender Sultan (sal.1409-1414) döneminde kent ön plana çıkmıştır. Ardından İbrahim Sultan'ın desteği ile Şiraz'daki üretim devam etmiştir. Ernst Grube (1963: 292) kentin İskender Sultan'ın (1409-1414) valilik yaptığı dönemde oldukça önemli bir merkez olduğunu ve pek çok el yazma üretildiğine vurgu yapmıştır. Şiraz'ın yerel yöneticilerin eline geçmesinden sonra Timurlu resim geleneğini Türkmen beylerine hizmet

\footnotetext{
${ }^{4}$ Şiraz hakkında bkz: Barthold, 1984:153-168.
} 


\section{Bir El Yazma Üretim Merkezi Olarak Şiraz ve Resim Üslubunun Türkmen Dönemindeki}

\section{Dönüşümü}

eden ressamlar tarafından kullanılmaya başlandığını ifade etmiştir. Karakoyunlu ve Akkoyunlu Döneminde Şiraz'da üretilen kitaplarda yeni resim üslubu oluştuğunu ve üslubun kademeli olarak ilerlediğini belirtmiştir.

Timurlulardan sonra, Şiraz'da Karakoyunlu hâkimiyeti, Cihanşah’ın (sal.1438-1467) 145253 yılında Fars bölgesini ele geçirmesinden sonra başlamıştır. Bir süre sonra Cihanşah Fars bölgesinin yönetimini oğlu Pir Budak'a bırakmıştır. Pir Budak’ın Şiraz kentindeki hâkimiyeti ile burada pek çok resimli el yazma eser hazırlanmıştır. Ancak bir süre sonra Cihanşah ve Pir Budak arasında yaşanan anlaşmazlık nedeniyle Pir Budak 1462 yılında Şiraz'da bulunan sanatçıları Bağdat'a götürmüştür' ${ }^{5}$ Karakoyunlu döneminde görülen hızlı değişim, Şiraz’ın bir yandan sanat merkezi olma özelliğini koruduğuna bir yandan da aynı dönemde Bağdat'ta var olan atölye ile etkileşim içerisinde olduğuna işaret eder.

Akkoyunlular döneminde, Şiraz’ın sanat merkezi olma durumu dönüşüme uğrayarak sürmüş, el yazma üretimi devam etmiştir. Uzun Hasan (hük. 1452-1478) Tebriz’i ülkenin merkezi haline getirmiş ve burada Heşt Behişt sarayını yaptırmıştır. Hasan'ın büyük bir sanat koruyucusu olduğu düşünülse de bu dönemde üretilen el yazmalarından günümüze ulaşan bir örnek bulunmamaktadır (İnal, 1995:155). Bu dönemde, Şiraz’ daki el yazma üretimi Halil Bey’in valiliği sırasında (val. 14711478) canlanmış, Yakup Bey’in (sal.1478-1490) döneminde de bu üretim desteklenmiştir.

Şiraz ile ilgili özellikle Akkoyunlu dönemine ait dönem kaynağı, Uzun Hasan'ın oğlu Halil Bey'in Şiraz'da 1471-1478 yılları arasındaki valiliği sırasında saray âlimlerinden Celaleddin Muhammed bin As'âd Dâvâni tarafından yazılan Arzname adlı eserdir ${ }^{6}$. Eserde Halil Bey’in hizmetinde çalışan hattat ve kâtiplerin sayısını vermiştir. Dâvâni’ye göre hattat ve kâtiplerin (nevîsandagân ve ehl-i kalem) toplam sayısı 360, kütüphane çalışanlarının (amele-yi kütübhâne-yi humâyun) ise 58 adettir (Minorsky, 1939: 159-160; Uluç, 2006: 32-33). Dâvâni’nin verdiği bu bilgilerden kitap sayısının fazlalığı Halil Bey döneminde Şiraz'da yoğun bir kitap üretiminin olduğunu anlaşılabilmektedir.

Şiraz, siyasi güç dengelerindeki tüm değişimlere rağmen, bazı dönüşümlere uğrayarak sürekliliğini ve sanat için bir merkez olma özelliğini koruduğu görülmektedir. Ayrıca güçlü sanat patronlarının buradaki sanat üretimini desteklemeleri en önemli etken olmuştur. Diğer taraftan üretim metodundaki yerel uygulamalar devamlılı̆̆ı sağlayarak çok sayıda eserin hazırlanmasına olanak sağlamıştır.

Bu aşamada Şiraz'daki resim üslubu, kitapların hazırlandıkları dönemlerdeki atölyelerin takip ettikleri yöntemin anlaşılmasını sağlayan bir unsur olarak karşımıza çıkmıştır. Diğer taraftan "ticari” terimi kullanılan kitapların büyük bir çoğunluğu Karakoyunlu ve Akkoyunlu dönemine aittir. Böylece bu iki beylik için kullanılan "Türkmen Dönemi" ve "ticari” terimleri bir arada değerlendirilmiştir. Bu iki kavram dâhilinde oluşan üslubu "Türkmen üslubu” denilmiştir.

Şiraz resim üslubunun Türkmen dönemindeki dönüşümünü anlayabilmek için daha erken evrelerine değinmek gerekir. 14. yüzyılın başından 15. yüzyılın ortasına kadar hazırlanmış olan nüshalar üzerinden Şiraz resim üslubunun, değerlendirmesini yapan Elaine Wright (2012: 156-157) üslubun özelliklerini üç kategoriye ayırmıştır. İlk özellik, insan ve hayvan figürlerinde görülen sadeleştirme ve stilizasyon; ikincisi, figürlerin, bulundukları mekânlara dikkatli, düzenli ve sade bir kompozisyonla yerleştirilmesi; üçüncüsü de kompozisyonun arka planının, renkler ve tasarım

\footnotetext{
5 Karakoyunlu Dönemindeki Şiraz ve Bagdat'ta üretilen el yazma örnekleri ve konu ile ilgili hususlar için bkz: ÇağmanTanındı, 1979: 23-25.

${ }^{6}$ Arzname adlı eser İstanbul Süleymaniye Kütüphanesi (Hamidiye 1438) bulunduğuna dair bilgi kaynaklarda geçmektedir.
} Eserin metni hakkında ayrıntılı inceleme için bkz: Minorsky, 1939: 141-178. 


\section{AYDIN}

uygulamaları ile dekoratif amaçlı kullanılması olmuştur. Ancak bu özelliklerin genel bir değerlendirme olduğunu, bazı farklılıklarla karşılaşmanın mümkün olduğunu da belirtmiştir.

Şiraz resim üslubunun genel özellikleri bu şekilde yorumlanırken, yerleşik hale gelen anlayışın devamı olarak görülen Türkmen dönemi resim üslubunun genel özelliklerine değinmek gerekir. Robinson (1958: 28-29)'a göre bu döneme ait resimlerde figürler kısa boylu ve iri başlıdır; bulutlar, bitkiler, kayalar ve ağaçlar ise resim içerisinde oldukça sınırlı şekilde yer alırlar. Zemin genellikle çok fazla değişikliğe uğramaz ve açık renk üzerine sadeleştirilmiş bitkiler yer alır. Bazen bu zemin, geleneksel ve geometrik şekilde yapılmış kayalıklı ufuk çizgisine sahipken bazen de ufuk çizgisi olmadan verilmiş ve yeşil rengin üzerine açık sarı ve yeşil tonlardan oluşan bitki öbekleri ile bütünleştirilmiştir. Kalabalık olmayan sahnelerde erkek figürlerin giydiği sarıklar genellikle beyaz, nadiren renkli ve başın üzerinde dolanmış şekildedir. Uzun elbiselerin üzerinde altın işlemeli desenler görülür. Erken dönem Türkmen resminde görülen kadın fïgürlerinin başlıkları Timurlu döneminde olduğu gibi beyaz renkli ve omuzlarına taşmış hâldedir ${ }^{7}$.

Türkmen üslubun kökeninin nereden geldiği konusunda, Robinson (1958: 26) üslubun başlangıcı hakkında kesin bir bilgi vermenin mümkün bir grup el yazmasının 15. yüzyılın başında Şahruh dönemi ile ilişkilendirilebileceğini ifade etmiş, Türkmen üslubunun, İran'ın kuzey ve kuzeybatısından yayılmış olabileceğini söylemiştir. The British Library'de bulunan 1446 tarihli Dunimarle Şehnamesi (Oriental 12688) ve 1468 tarihli Şirvan Antolojisi'nin (Add MS 16561) bu üslubu devam ettirdiğini ve köken olarak kuzeybatı İran’a dayandırıldığını söylemiştir.

İnal (1972: 163) Robinson'un işaret ettiği üslubun Dunimarle Şehnamesi’nde görüldüğü belirtmekle birlikte, onun görüşünü kabul eder ve üslubun asıl merkezinin Şiraz olduğu konusuna vurgu yapar.

Türkmen üslubuna dair en erken örnekler, The British Library'de bulunan, Robinson'un (1958:26) tarihsiz olarak belirttiği ancak yaklaşık 1430 yıllarına Şehname nüshası (Oriental 4384) ve Princeton University Library'de bulunan Nizami Hamsesidir (Hittti 7) ${ }^{8}$. Ayrica Hz. Ali'nin yaşamını konu edinen Havername de erken örnekler arasındadır. Bu eserin 155 resimli sayfası vardır ve bu sayfaların bazıları Chester Beatty Library'de (Per 293.7) bulunmaktadır'.

Robinson (1958: 27), Türkmen üslubunun ana merkezi olarak Şiraz’1 göstermiş ve üslubun Şiraz'da 15.yüzyılın ortalarında devam ettiğini belirtmiştir ${ }^{10}$. Yazar, Türkmen üslubunun Şiraz ile olan bağlantıları konusunda sınırlandırma yapmıştır. Bu sınırlandırmaya göre ilk grubu, ŞirazTimurlu üslubu (1440-1460); ikinci grubu, Şiraz ve İsfahan bağlantılı olarak 1474-1486 yıllarında görülen Türkmen üslubu; üçüncü grubu, 1482-1513 yılları arasına tarihlendirilen ve yedi el yazmasında görülen Türkmen üslubu; son grubu ise 1500-1520 Türkmen üslubundan Şiraz-Safevi üslubu geçilen evreyi gösteren Şirazlı kâtiplerin hazırladığı bir düzine yazma oluşturmaktadır ${ }^{11}$.

Karakoyunlu dönemi resim sanatını inceleyen Atılgan (2000: 67-74) Türkmen dönemi resim sanatı ile ilgili Karakoyunlu dönemine dikkat çekmiştir. Öte yandan Şiraz'daki Türkmen dönemi üretiminin, ağırlıklı olarak Akkoyunlu dönemi ürünleri olduğu görülmektedir. Sanat üretiminin

\footnotetext{
${ }^{7}$ Robinson'un belirttiği üslup özellikleri araştırmacılar tarafından kabul görmüştür. Bkz. Titley, 1983: 66; İnal, 1995:149; Atılgan, 2000: 64. Türkmen dönemi resim üslubunun 1470-1500 yılları arasındaki Şehname örnekleri üzerinden değerlendirilmesi için bkz: Aydın, 2019: 58-61.

${ }^{8}$ Kütüphanenin güncel dijital kataloğundan yapılan incelemede belirtilen tasnif numarasından esere ulaşılamamıştır. Dijital katalog için bkz. https://catalog.princeton.edu/?page=7\&q=1446\&search_field=all_fields (Erişim: 10.07.2019).

${ }^{9}$ Sayfalar için bkz. https://viewer.cbl.ie/viewer/object/Per_293_7/2/ (Erișim: 10.07.2019).

${ }^{10}$ Atılgan, 2000 yılında hazırladığı "15. yüzyıl Karakoyunlu Türkmen Minyatürleri” başlıklı tezinde Türkmen üslubunu ayrı bir başlık altında değerlendirmiş ve Robinson’un bu üslupla ilgili görüşlerini ayrıntılı bir şekilde ele almıştır. Bkz. Atılgan, 2000: $62-74$

11 Robinson'un yapmış olduğu sınıflandırmada birinci ve ikinci grupta olanlar daha çok Karakoyunlu ve Akkoyunlu dönemlerine ve çoğunlukla da Şiraz'da üretimin olduğu döneme denk gelmektedir.
} 


\section{Dönüşümü}

Akkoyunlu döneminde artış göstermesi, Türkmen üslubunun şekillenmesine büyük ölçüde olanak sağlamış, bunda Şiraz atölyesinin 15 . yüzyılın sonuna kadar yaptığı üretim etkili olmuştur.

Türkmen döneminde resim üslubu, Şiraz’da o güne dek İlhanlı, Celayirli, İncü ve Timurlu gibi güçlü sanat hamileri için çalışan nakkaşhanelerin oluşturduğu alt yapı üzerinde şekillenmiştir. Ayrıca Timurlular döneminde öne çıkan Herat okulu sanatçılarının, Karakoyunlu hükümdarı Pir Budak'ın Herat'ı ele geçirmesinin (1458) ardından Şiraz'a getirilmesi, aynı dönemde Bağdat nakkaşhanelerinin üretimi ve Akkoyunlu Uzun Hasan'ın Tebriz'deki faaliyetlerinin etkileri de göz önünde bulundurulmalıdır. Türkmen dönemi resim sanatının, Karakoyunlu döneminde, özellikle Celayirli ve Timurlu dönemine ait birtakım özellikleri bünyesine alarak sürdürmesi ve Akkoyunlu döneminde hâkimiyet alanıyla birlikte sanat merkezinin değişmesi, Şiraz üslubunun şekillenmesinde etkili olmuştur ${ }^{12}$.

Özetle, resim üslubunun, Karakoyunlu ve Akkoyunlu döneminde yeniden şekillendiği söylenebilir. İki beyliğin resim sanatları arasında belirgin bir farklılıktan söz etmek oldukça güç olsa da Türkmen dönemi resim üslubunun Akkoyunlu döneminde güçlendiğini ve yerleşik hale gediğini söylemek mümkündür. Özellikle bu dönemden günümüze ulaşan eser sayısının daha fazla olması konu hakkında daha fazla veri elde edilmesine olanak sağlamıştır.

\section{SONUC}

Önemli yazma üretim merkezlerinden biri olarak Şiraz farklı politik güçlerin hakimiyeti altında kalan, konumu sebebiyle de ticari faaliyetin etkinliğini koruduğu bir kent olmuştur. Kentte, zaman zaman yerel yöntemleri de kullanarak devamlılığı olan bir üretim biçimi oluşturulmuştur. $\mathrm{Bu}$ devamlılık içerisinde Şiraz resim üslubu belirli sınırları ve kuralları olan fakat zamanla çeşitli değişim ve dönüşümlerle 15. yüzyılın sonuna taşınan bir üslup haline gelmiştir. Öte yandan, resim üslubunun şekillenmesinde en başta Şiraz nakkaşhanelerinin benimsediği birtakım özellikler etkili olmuştur. Dolayısıyla çalışmada ele alınan dönemdeki üslubu, Türkmen Dönemi resim üslubu yerine Şiraz resim üslubunun Türkmen devrindeki yeni yorumu olarak değerlendirmek uygun olacaktır.

\footnotetext{
12 Resim sanatının şekillenmesi hakkında bkz. Robinson, 1958; 1967; 1991; Kühnel. 1964-65; Titley, 1983; ÇăgmanTanındı, 1979: İnal,1995; Wright, 2012. Ayrıca bkz: Aydın 2019: 55-58. Bu konu hakkında bahsedilen hususlar ve ayrıntılı bilgi için bkz: Aydın, 2019:55-61. Bu döneme dahil edilen, 1470-1500 yılları arasında hazırlanan Şehname örneklerinin resimleri için bkz: Aydın, 2019.
} 


\section{AYDIN}

\section{KAYNAKÇA}

Aka, İ. (2012). Timurlular. Türkiye Diyanet Vakfi İslam Ansiklopedisi, C. 41. İstanbul: Türkiye Diyanet Vakfı Yayınları, s.177-180.

Akimushkin, O. F. ve Ivanov. A. A. (1979). The Art of Miniature Painting. The Arts of the Book in Central Asia, 14th- 16th Centruies (Ed. B. Gray). USA: Shambhala Publications, s. 35 - 59.

Atılgan, S. (2000). 15. Yüzyıl Karakoyunlu Türkmen Minyatürleri (2 cilt). Yayımlanmamış Doktora Tezi: İstanbul: Mimar Sinan Üniversitesi, Sosyal Bilimler Enstitüsü.

Aydın, D. (2019). Şiraz Nakkaşhaneleri ve Resimli Şehnameler (1470-1500). Yayımlanmamış Doktora Tezi: Ankara: Hacettepe Üniversitesi, Sosyal Bilimler Enstitüsü.

Bağcı, S. (1993). Takdim Minyatürlerinde Farklı Bir Konu: Süleyman Peygamber'in Divanı. Sanat Tarihinde İkonografik Araştırmalar Güner Inal'a Armă̆an. Ankara: Hacettepe Üniversitesi Yayınları, s. 35-59.

Barbaro, J. ve Contarini, A. (1873). Travels Tana and Persia. (Lord Stanley of Alderley, Ed.), (W. Thomas, Çev.), New York: Burt Franklin Publisher.

Barhold, W. (1984). An Historical Geography of Iran (Çev: S. Soucek, Ed, S. E. Bosworth). New Jersey: Princeton University. Press, s. 148-168.

Çağman, F. ve Tanındı, Z. (1979). Topkapı Sarayı Müzesi İslam Minyatürleri. İstanbul: Güzel Sanatlar Matbaası.

Gray, B. (1986). The Pictorial Arts in The Timurid Period. (Ed. P. Jackson - L. Lockhart). The Cambridge History of Iran, the Timurid and Safavid Period, 6, s. 843 - 876.

Grube, E. (1963). The Miniatures of Shiraz. The Metropolitan Museum of Art Bulletin, New Series, 21/ 9, s. 285 - 295. http://www.jstor.org/stable/3257942, (Erişim: 22.04.2016).

Gündüz, T. (2008). Safevîler. Türkiye Diyanet İslam Ansiklopedisi, C. 35. İstanbul: Türkiye Diyanet Vakfı Yayınları, s. 451-457.

İnal, G. (1972). Topkapı Sarayı Müzesindeki Şehname Yazmalarının Minyatürleri Üzerinde Analitik Bir Çalışma. İstanbul: Doçentlik Tezi.

İnal, G. (1995). Türk Minyatür Sanatı, Başlangıcından Osmanlıya Kadar. Ankara: Atatürk Kültür Merkezi Yayını.

Kurtuluş, R. (2000), İncular. Türkiye Diyanet Íslam Ansiklopedisi, C. 22. İstanbul: Türkiye Diyanet Vakfi Yayınları, s. 280-281.

Kühnel, E. (1964-65). History of Miniature Painting and Drawing. A Survey of Persian Art from Prehistoric Times to the Present. (Ed. A. U. Pope). London and New York: Oxford University Press, 5, s. 1829-1897.

Limbert, J. (2004). Shiraz in The Age of Hafez, The Glory of A Medieval Persian City. United States of America: University Washington Press.

Minorsky, V. (1939). A Civil and Military Review in Fārs in 881/1476, Bulletin of the School of Oriental Studies, 10/1, s. 141 - 178. https://www.jstor.org/stable/607930, (Erişim: 08.07.2019).

Özgüdenli, O. Gazi., (2010). Şiraz. Türkiye Diyanet Vakfi İslam Ansiklopedisi, C. 39. İstanbul: Türkiye Diyanet Vakfı Yayınları, s. 182-184. 
Bir El Yazma Üretim Merkezi Olarak Şiraz ve Resim Üslubunun Türkmen Dönemindeki

Dönӥşйтӥ

Robinson, B. W. (1958). A Descriptive Catalogue of the Persian Paintings in The Bodleian Library. Oxford: Clarendon Press.

Robinson, B. W. (1967). Persian Miniature Painting from Collections in The British Isles. London: Her Majesty's Stationery Office.

Sümer, F. (1989), Akkoyunlular. Türkiye Diyanet Vakfi İslam Ansiklopedisi, C. 2. İstanbul: Türkiye Diyanet Vakfi Yayınları, s. 270-274.

Sümer, F. (2001), Karakoyunlular. Türkiye Diyanet Vakfi İslam Ansiklopedisi, C. 24. İstanbul: Türkiye Diyanet Vakfi Yayınları, s. 434-438.

Titley, N. M. (1983). Persian Miniature Painting: Its Influence on the Art of Turkey and India: The British Library Collections. London: British Library.

Uluç, L. (2006). Türkmen Valiler, Şirazlı Ustalar, Osmanlı Okurlar: XVI. Yüzyll Şiraz Elyazmaları. İstanbul: İş Bankası Yayınları.

Uzunçarşıl1, İ. H. (1969). Anadolu Beylikleri ve Akkoyunlu, Karakoyunlu Devletleri. Ankara: Türk Tarih Kurumu Yayınları.

Wright, E. J. (2012). The Look of The Book: Manuscript Production in Shiraz, 1303-1452.

USA: University of Press.

https://catalog.princeton.edu/?page=7\&q=1446\&search_field=all_fields_Erişim: 10.07.2019).

https://viewer.cbl.ie/viewer/object/Per_293_7/2/ (Erişim: 10.07.2019). 